\title{
Wayang untuk Dalang Multi Level Usia Sebagai Wahana Pelestarian Seni Tradisional
}

\author{
Junaidi, Bayu Aji Suseno, dan Abdul Aziz \\ Institut Seni Indonesia Yogyakarta
}

\begin{abstract}
Abstrak
Penelitian ini bertujuan untuk melestarikan wayang tradisi melalui dalang berbagai usia. Wayang tradisi bersifat mono level dan diformat untuk dalang laki-laki dewasa, sehingga kurang sesuai dengan dalang multi level usia. Mengapa model wayang format multi usia dapat dijadikan sebagai wahana pelestarian wayang tradisional? Jawaban pertanyaan ini dapat diperoleh melalui perancangan model wayang berukuran fisik dan jiwa dalang berbagai level usia. Metode eksperimen digunakan untuk menciptakan wayang multi format, sedangkan pembahasannya berdasarkan teori struktur. Lima macam format boneka wayang kulit purwa dapat dihasilkan untuk diterapkan kepada dalang anakanak, anak, remaja awal, remaja akhir, dan dewasa, yaitu: (1) Wayang kaper, untuk dalang tingat anak-anak; (2) Wayang kidangkencanan untuk dalang tingkat anak; (3) Wayang jaranan, untuk dalang tingkat remaja awal; (4) Wayang banthèngan, untuk dalang tingkat remaja akhir; dan (5) Wayang gajahan, untuk dalang tingkat dewasa. Kelima jenis wayang ini dapat dipakai sebagai wahana untuk pelestarian seni tradisional, karena memiliki kesesuaian format fisik dan jiwanya.
\end{abstract}

Kata kunci: Wayang, dalang multi usia, wahana, pelestarian, dan seni tradisional.

\begin{abstract}
This study aims to preserve traditional wayang through various age masterminds. Traditional puppets are mono level and formatted for adult male puppeteers, so that they are less in line with multi-age masterminds. Why can the multi-age wayang model be used as a vehicle for traditional wayang preservation? The answer to this question can be obtained through the design of a physical puppet model and the mastermind soul of various ages. The experimental method is used to create multi-format puppets, while the discussion is based on structural theory. Five types of purwa puppet puppet formats can be produced to be applied to the puppeteers of children, children, early adolescents, late adolescents, and adults, namely: (1) Kaper puppets, for the children's puppeteers; (2) Kidangkencanan puppets for child-level puppeteers; (3) Wayang jaranan, for the early adolescent level masterminds; (4) Wayang banthngangan, for the final youth level mastermind; and (5) Wayang gajahan,
\end{abstract}


to mastermind the adult level. These five types of puppets can be used as a vehicle for the preservation of traditional art, because it has the suitability of the physical format and soul.

Keywords: Puppet, multi-age mastermind, vehicle, preservation, and traditional art.

\section{PENDAHULUAN}

Wayang kulit purwa dibuat dari kulit kerbau/lulang kebo atau sapi/lembu, dipahat/ ditatah, diwarnai/disungging, diberi psenggapit/ digapiti, diberi tuding/ditudingi, dipakai sebagai alat peraga, diperankan sebagai tokoh-tokoh dalam suatu cerita, sehingga wujudnya menggambarkan suatu kehidupan alam semesta ciptaan Tuhan, berupa sosok manusia (manungsa), raksasa (buta), kera (réwanda), makluk halus (sétanan), binatang (kéwanan), pohon(kayon), rumah (dalem), senjata (pusaka), dan perlengkapan rumah tangga (prabot). Masing-masing memiliki identitas, wujud, dan karakter, seperti misalnya tokoh wayang bernamaArjuna, berwujud manusia tampan, dan berkarakter tenang/ protagonis, sebaliknya bernama Buta Cakil, berujud raksasa jelek, dan berkarakter jahat/ antagonis. Keduanya sebagai oposisi biner yang selalu muncul bersama dalam suatu pertunjukan dan selalu berkonflik fisik maupun spikisnya. Lebih luas lagi, bahwa wujud wayang menandai secara lahiriyah tentang peranan, fungsional, usia, kelamin, kedudukan, karakter, dan kadangkadang suasana hatinya (Holt, 1967: 427). Dengan demikian, maka wayang memiliki multi arti, yakni sebagaiboneka, tokoh, dan pertunjukan/ pementasan/wayangan/pakeliran, sehingga memiliki ketentuan jumlah, ukuran, dan wujud sebagai pengungkap karakternya.

Jumlah, ukuran, dan wujud wayang telah ditentukan dalam rangka memenuhi kebutuhan penokohan yang bersifat variatif disesuaikan dengan kemampuan kolektornya, yakni dipaket dalam satu kotak atau satu set (sekothak) biasanya berisi minimal 180-250 biji, tetapi bisa mencapai 500 biji (Soetrisno, 1974: 1). Berbeda lagi, bahwa wayang dianggap lengkap apabila mencapai jumlah 378 biji, dan cukupan untuk lingkungan para dalang (padhalangan) berjumlah 197 biji (Sajid, 1958: 25-40 dan 91-97), bahkan menurut data di Paheman Radyapustaka dan Pura Mangkunagaran lain lagi, yakni berjumlah 471 biji (Darsomartono, 1978: 18). Ukuran wayang satu set tersebut ada delapan macam, yaitu: (1) Paling cilik/paling cilik atau sakbayèn; (2) Cilik/kecil atau sakputrèn; (3) Sedheng/ sedang atau sakbambangan; (4) Tanggung/ tanggung sakkatongan; (5) Dhara/di atas tanggung atau saktatagan; (5) Magak/mendekati besar atau sakboma; (7) Gedhé/besar atau sakdugangan; dan (8) Paling gedhé/paling besar atau sakbutoraton (Junaidi, 2010: 491).

Selain itu, wayang kulit purwa dibuat dengan empat macamjenis ukuran, yakni: (1) Jenis ukuran kecil disebut kaper, digunakan untuk persediaan alat permaian bagi anak-anak yang suka tentang kesenian wayang (piranti dolanan); (2) Jenis ukuran tanggung/sedheng/tengahan disebut kidangkencanan, digunakan untuk memperingan tugas dalang agar tidak keberatan/ngaya (ngènthèngaké dhalang); (3) Jenis ukuran normal/umum/lumrah disebut padhalangan, digunakan untuk para dalang pada umumnya (dienggo mayang déning dalang lumrah); dan (4) Jenis ukuran besar/ageng disebut wayang jujudan, digunakan untuk para dalang di lingkungan keraton yang memiliki tempat luas (njumbuhaké papan kang jembar) (Sajid, 1958: 80-82). Dengan demikian, ukuran wayang 
bersifat sejenis dan lain jenis, yakni berdasarkan satu kelompok dan beda kelompok.

Bentuk wayang kulit purwa bergaya ekspresif dekoratif(manusia, raksasa, dan kera), ekspresif dekoratif humoris karikatur (panakawan dan dhagelan), kelompok (rampogan), binatang (gajah, kuda, naga), senjata (panah, gada, keris), dan roh halus (Soekatno, 1992: 13), maksudnya wujud ekspresif adalah sangat berlainan dengan bentuk yang digambarkan (Haryanto, 1991: 18), seperti: organ tubuh (rambut, dahi, alis, bulu mata, hidung, kumis, mulut, gigi, bibir, pipi, dagu, telinga, leher, bahu, tangan, tubuh, dan kaki), busana (baju, celana, dan kain panjang) dan aksesorisnya (mahkota, sumping, anting, gelang, kalung, dan sebagainya). Wujud anatomi, busana, dan aksesoris tersebut mengacu pada tumbuhan dan buah-buahan, binatang, dan benda alam, seperti misalnya grana bentulan (hidung seperti buah bentul atau soga), kampuh parangrusak (kain panjang seperti batu karang yang tekena percikan air samodera), lathi manggis karengat (bibir seperti buah manggis dikupas), kelatbau nagamangsa (gelang lengan seperti naga yang sedang makan), dan sebagainya. Ketiga unsur tersebut dipakai untuk menggambarkan karakter masing-masing tokoh, secara implisit dan eksplisit diungkapkan oleh dalang melalui tampilan gerak (sabetan), tampilan suara (caturan), dan tampilan lagu (sulukan).

Pada masa pra-sejarah wayang dimainkan oleh kepala rumah tangga yang memiliki kemampuan spiritual tinggi atau seorang dukun/syaman, tetapi dalam perkembangannya bisa dimainkan oleh seseorang yang memiliki keahlian atau kejuruan khusus disebut dalang profesional (Sastroamidjojo, 1964: 88), maka predikat dalang tersebut hanya bisa dimiliki oleh orang dewasa atau tua, sehingga peralatan boneka wayangnya berukuran orang dewasa pula, yaitu disebut wayang padhalangan/umum/normal/standar, maksudnya seperangkat wayang ukuran normal yang biasa digunakan oleh para dalang (Sajid, 1958: 81). Namun demikian, sejak tahun 1910-an muncul dalang berusia anak Sudirman dari Klaten dan Sutarno dariWonogiri, dan kemudian berlanjut bermuncalan dalang remaja pula, bahkan sekarang tersebar di berbagai wilayah Negara Kesatuan Republik Indonesia seperti: Sumatera, Kalimantan, Sulawesi, Papua, dan sebagainya, jumlahnya mencapai ratusan anak/remaja. Namun demikian, munculnya dalang multi level usia tersebut belum diimbangi dengan tersedianya alat utama berupa boneka wayang berstandar format bertingkat, yakni haruslah sesuai dengan keadaan kejiwaannya (Suryabrata, 2004: 184185). Berbagai level usia dalang ternyata masih menggunakan wayang format padhalangan, sehingga bagi remaja dan anak mengalami kendala-kendala yang bersifat fisik dan psikis. Untuk itu, maka diperlukan model wayang berformat multi level jumlah, ukuran, dan bentuk agar tercipta model wayang berstandar bertingkat dan tercapai secara teknik, ekspresi, dan esensinya. Mengapa model wayang format multi usia dapat dijadikan sebagai wahana pelestarian wayang tradisional?

\section{METODE}

Penelitian Skema Strategis Nasional berjudul "Wayang Perspektif Pendidikan Nasional", dilakukan untuk mencarijawabannya. Penelitian ini bersifat tindakan kelas, yakni mampu menawarkan cara dan prosedur baru untuk memperbaiki dan meningkatkan profesionalisme (Suroso, 2009: 19). Jenis penelitian ini menawarkan cara atau prosedur baru untuk merumuskan wayang berstandar multi level, agar tampilan dalang multi level usia bisa lebih proporsional, karena sesuai dengan tingkatan fisik dan kejiwaannya. Kajian data berdasarkan jumlah, ukuran, dan bentuk 
wayang disesuaikan dengan kemampuan fisik dan kejiwaan pada setiap level, maka metode eksperimen digunakan untuk mengungkapkan hubungan sebab-akibat antara variabel (Nawawi dan Martini, 2005: 130), yakni hubungan antara variabel narasi/catur dan gerak/sabet yang ditimbulkan dari format wayang. Langkah pertama dilakukan observasi melalui kajian pustaka dan lapangan, agar memperoleh gambaran tentang format yang ada berserta tingkat permasalahannya. Langkah kedua melakukan perancangan untuk mewujudkan format multi level, dengan mempertimbangkan jumlah, ukuran, dan bentuk. Analisa data menggunakan teori struktur yang mendasarkan tiga sifat, yaitu: (1) Totalitas, maksudnya terdiri dari berbagai unsur yang menyatu yaitu pahatan, sunggingan, dan gapitan; (2) Transformasi, yakni mengalami perubahan wujud dari bentuk asalnya yaitu dari wayang padhalangan ke wayang multi level; dan (3) Pengaturan diri, artinya unsur-unsur yang berbeda wujud dan aturannya tetapi saling terkait yaitu anatomi, busana, dan aksesoris (Piaget, 1995: viii-ix). Ketiga sifat ini dipakai untuk melakukan pembahasan tentang format wayang kulit purwa untuk dalang multi level usia, yakni anak-anak, anak, remaja awal, remaja akhir, dan dewasa.

\section{HASIL DAN PEMBAHASAN}

Format merupakan bentuk atau ukuran yang dipakai untuk menentukan suatu model, dalam hal ini adalah model wayang kulit purwa, untuk dalang anak-anak, anak, remaja awal, remaja akhir, dan dewasa atau jika pada tingkat pendidikan adalah level PAUD, SD, SMP, SMA, dan PT. Pembuatan wayang secara fisik dan psikis bertingkat mulai paling sedikit sampai paling banyak (jumlah/totalitas), mulai dari paling kecil sampai paling besar(ukuran/transformasi), dan mulai dari paling sederhana sampai paling rumit (bentuk/pengaturan diri). Tingkatan tersebut dijadikan lima format dengan identitas meminjam lima macam binatang agar terjadi konsistensi penamaan, yaitu: (1) Wayang kaper untuk dalang level anak-anak; (2) Wayang kidangkencanan untuk dalang level anak; (3) Wayang jaranan untuk dalang level remaja awal; (4) Wayang banthèngan untuk dalang level remaja akhir; dan (5) Wayang gajahan untuk dalang level dewasa. Jumlah, bentuk, dan ukuran masingmasing level dapat dijabarkan dengan berdasarkan tiga sifat dalam teori struktur, yaitu totalitas, transformasi, dan pengaturan diri sebagai berikut.

\section{FORMAT WAYANG KAPER UNTUK DALANG LEVELANAK-ANAK}

Pembuatan wayang level anak-anak masih konsisten disebut "wayang kaper", maksudnya berukuran kecil jika dimainkan seperti binatang kaper (kupu kecil). Secara totalitas berjumlah paling sedikit, yakni minimal 30 (tigapuluh) sampai 36 (tigapuluh enam) buah atau tokoh peraga, terdiri atas tokoh anak-anak manusia berkarakteristik ekspresikekanakan (Pandawa dan Kurawa masa anak-anak), tokoh berkarakteristik ekspresi humoris atau lucu (Panakawan), binatang berkarakteristik ekspresi karnifora dan herbifora (jinak dan buas), dan rumah berlatarbelakang rumah. Jumlah tokoh wayang berupa manusia berusia anak mencapai 17 tokoh (Yudistira, Bima, Arjuna, Pinten, Tangsen, Duryudana, Dursasana, Durmagati, Kartamarma, Citraksa, Citraksi, Udawa, Kakrasana, Narayana, Laraireng, Larasati, dan Adimanggala), manusia berusia dewasa 5 tokoh (Pandu, Kunti, Madrim, Destarata, dan Gendari), manusia berusia tua 4 tokoh (Semar, Gareng, Petruk, dan Bagong), binatang 9 ekor (gajah, banteng, kuda, babi hutan, harimau, kijang, ular, ikan, dan garuda), dan kayon atau gunungan 1 biji. Jumlah tokoh wayang berusia anak-anak mendominasi bisa mencapai $\pm 48 \%$ (lebih kurang empatpuluh 
delapan persen), dengan pertimbangan dunia anak-anak. Wayang berusia dewasa dan tua mencapai $\pm 25 \%$ (lebih kurang duapuluh lima persen), dengan pertimbangan bukan dunia orang dewasa dan tua. Wayang binatang mencapai $\pm 25 \%$, dengan pertimbangan dunia anak-anak dekat dengan dunia binatang (lebih kurang duapuluh lima persen). Wayang kayon/gunungan mencapai $\pm 2 \%$ (lebih kurang dua persen), dengan pertimbangan belum menjadi dunianya.

Transformasi dalam wayang kaper diwujudkan dalam bentuk, yakni menggambarkan fisik dan jiwa anak-anak dengan ekspresi meliputi: (1) owah, (2) luruh, (3) kendel, (4) grasak, (5) lanyap, (6) sabar, (7) ladak, (8) lucu, dan (9) culika. Wujud anatomi, busana, dan aksesoris menampakkan figur anak-anak, yakni lebih bersifat realitas dan sederhana, seperti bentuk mata berwarna putih hitam seperti warna mata manusia biasa, bentuk mulut belum memakai salitan sehingga terkesan berpipi padat, macam dan warna busana sederhana dengan menerapkan warna blok, sedangkan aksesoris yang digunakan bersifat minimalis karena belum waktunya gemar berias dan berhias. Tanda fisik lainnya, yakni belum munculnya jenggot, kumis, dan simbar bagi wayang laki-laki, sedangkan wayang wanita belum tampak payudaranya. Pada tingkat anak ini, persoalan yang disampaikan harus sesuai dengan orientasinya, agar tidak terjadi kesalahan format. Sifat owah/berubah, luruh/tenang, getapan/emosional, kendel/pemberani, grasak/kasar, lanyap/periang, wengis/ kejam, sabar/sabar, ladak/sombong, dan lucu/ humor perlu diapresiasi oleh anak, agar bisa membedakan mana yang baik dan yang buruk. Tentu saja sifat tenang, pemberani, sabar, periang, dan jenaka sangat baik untuk dimiliki, sedangkan sifat berubah-ubah, emosional, kasar, kejam, dan sombong tidak pantas untuk dimiliki. Sifat transformasi diwujudkan dalam bentuk yang mencerminkan karakter dan ekspresi keknakan, kelucuan, jinak dan buas. Keindahan dan kemegahan merupakan fantasidalam dunia kekanakan, yang masih terkesan lucu dan bebas untuk melakukan aktivitas secara terbimbing.

Pengaturan diri berupa pengaturan ruangan anatomi, busana, dan aksesoris sama sepertipada wayang padhalangan, sepertimisalnya anatomi mata gabahan berpasangan dengan hidung walimiring dan bertubuh maksimal sembada, tetapi untuk memudahkan permainan dan karakter kurang baik (sombong dan congkak) maka anakanak Kurawa bertangan gerak satu (tangan depan lepas dan tangan belakang malangkerik permanen). Busana dan aksesoris kampuh jangkahan, bokongan, bebetan, jamang, sumping, garudha mungkur, dan makutha.

Ukuran wayang jenis kaper ini ada enam macam, yaitu: (1) Kecil atau kerdil, bertinggi badan \pm 24 centimeter sepertiGareng; (2) sedang atau sebambang, bertinggi badan \pm 27 centimeter seperti Pinten; (3) Tanggung atau seputra halus, bertinggi badan \pm 30 centimeter seperti Arjuna; (4) Tanggung atas atau seputra tangguh, bertinggi badan \pm 34 centimeter seperti Durmagati; (5) Besar atau seputra gagah, bertinggi badan \pm 37 centimeter seperti Bima; dan (6) Sangat besar atau sepohon bertinggi \pm 40 centimeter seperti kayon dan gajah. Dengan enam macam ukuran ini dalang pada tingkat usia anak-anak dapat memainkan wayang secara layak, baik gerak dan suaranya. Layak suara berdasarkan warna suara kecil, jika menggunakan nada gamelan berada pada wilayah nada $1 /$ ji/panunggul bawah sampai 1 atas, atau sakgembyangan, sedangkan layak gerak terjadi adanya kesesuaian organ tubuh wayang berukuran sangat kecil dan lincah dengan dalang anak-anak yang masih kecil pula dalam lingkup fantasi bermain. Pengaturan diri berupa 
perubahan ukuran wayang pedhalangan ke wayang kaper, yakni berkurang atau mengecil 7 sampai 38 centimeter.

\section{FORMAT WAYANG KIDANGKENCANAN UNTUK DALANG LEVELANAK}

Peraga atau tokoh wayang kidangkencanan untuk level anak masih sedikit jumlahnya, yaitu secara totalitas satu peti atau satu set minimal 72 dan maksimal ada 86 (delapanpuluh enam) dan ukurannya kecil, disebut "wayang kidangkencanan", maksudnya seperti binatang kijang mas. Peraga-peraga wayang diambilkan dari sebagian kisah Mahabarata, Ramayana, dan dunia binatang. Adapun golongannya, yaitu: (1) Wayang Pandawa Lima, (2) Sebagian wayang Kurawa diambil tujuh tokoh, (3) Orang tua dan pengasuh para Pandawa, (4) Orang tua dan pengasuh Kurawa, (5) Wayang Rama dengan saudaranya, (6) Wayang Rahwana dengan saudaranya dan seangkatannya, (7) Wayang Bambang Senggana dan seangkatannya, (8) Wayang binatang, dan (9) Kayon. Dengan jumlah tujuhpuluh dua sampai delapanpuluh enam biji boneka wayang tersebut sudah bisa untuk memainkan berbagai cerita dalam Mahabarata dan Ramayana, seperti misalnya Pandawa Anak Berbakti, Kurawa Anak Nasar, Rama Anak Santun, Rahwana Anak Serakah, dan sebagainya. Jumlah tersebut didominasi oleh tokoh usia anak, yakniberjumlah 59 tokoh atau $78 \%$, sehingga bisa menunjukkan atmosfir dunia anak.

Ekspresi wayang kidangkencanan sebagai perwujudan sifat transformasi, yakni(1) owah, (2) luruh, (3) getapan, (4) kendel, (5) grasak, (6) lanyap, (7) wengis, (8) sabar, (9) ladak, (10) lucu, dan(11) culika. Sifat owah/berubah, luruh/tenang, getapan/emosional, kendel/ pemberani, grasak/kasar, lanyap/periang, wengis/ kejam, sabar/sabar, ladak/sombong, dan lucu/ humor perlu diapresiasi oleh anak, agar bisa membedakan mana yang baik dan yang buruk. Tentu saja sifat tenang, pemberani, sabar, periang, dan jenaka sangat baik untuk dimiliki, sedangkan sifat berubah-ubah, emosional, kasar, kejam, dan sombong tidak pantas untuk dimiliki. Secara filosofi binatang kijang menggambarkan tindakan yang lincah seperti anak diusia sekitar 7-12 tahun. Pada tingkat anak ini, persoalan yang disampaikan sesuai dengan orientasinya, yakni kekanakan.

Ukuran wayang jenis kidangkencanan ini ada enam macam, secara pengaturan diri dibuat dalam enamukuran, yaitu: (1) Kecil atau seputri, bertinggibadan \pm 27 centimeter sepertiDursilawati; (2) sedang atau sebambang, bertinggi badan \pm 30 centimeter seperti Abimanyu; (3) Tanggung atau seputra halus, bertinggi badan \pm 36 centimeter seperti Arjuna; (4) Tanggung atas atau seputra tangguh, bertinggibadan \pm 40 centimeter seperti Gatutkaca; (5) Besar atau seputra gagah, bertinggibadan \pm 45 centimeter sepertiBratasena; dan (6) Sangat besar atau seputra gagah tambun bertinggi badan \pm 50 centimeter seperti Kumbakarna. Dengan enam macam ukuran ini dalang pada tingkat pendidikan Sekolah Dasar dapat memainkan wayang secara layak, baik gerak dan suaranya. Layak suara berdasarkan ambitus suara anak dengan mayoritas tokohtokoh wayang berusia anak, sedangkan layak gerak terjadi adanya kesesuaian organ tubuh wayang dengan dalang anak.

\section{FORMAT WAYANG $J A R A N A N$ UNTUK DALANG LEVEL REMAJAAWAL}

Peraga atau tokoh wayang jaranan untuk dalang remaja awal secara totalitas berjumlah cukupan, yaitu satu peti atau satu set minimal 108 dan maksimal 185 (seratus delapanpuluh lima) atau diturunkan setingkat dari wayang untuk remaja akhir, disebut jenis "Wayang Jaranan", 
maksudnya seperti binatang kuda yang secara ukuran tubuh di bawah banteng. Totoh yang ditampilkan adalah remaja awal Pandawa dan Kurara beserta sahabat-sahabatnya, rama beserta saudara-saudaranya, Rahwana beserta saudarasaudaranya, Arjunasasra beserta sahabatsahabatnya, Sambu beserta saudara-saudaranya, binatang, senjata, dan benda alam. Dengan tokohtokoh ini bisa untuk menampilkan cerita-cerita yang bersumber pada Epos Ramayana, Epos Mahabarata, Serat Arjunasasra, Para Dewa, binatang, dan perlengkapannya, seperti Arjuna Mencari Kawan, Duryudana Mencari Musuh, Rama Remaja Alim, Rahwana Remaja Sombong, Sumantri-Sukasrana, Brahma Remaja Pemberani, dan sebagainya.

Ekspresi wayang jaranan secara transformasi terdiri : (1) owah, (2) luruh, (3) getapan, (4) kendel, (5) grasak, (6) lanyap, (7) wengis, (8) sabar, (9) ladak, (10) lucu, dan (11) culika. Dibanding dengan ekspresi dalam wayang Sekolah Menengah Atas masih sama karena pada tingkat remaja, tetapi raut muka dan tubuh lebih tampak muda. Dintandai dengan belum munculnya jenggot, kumis, dan simbar bagi wayang laki-laki, sedangkan wayang wanita masih berpayudara kecil. Pada tingkat remaja awal ini, persoalan yang disampaikan harus sesuai dengan orientasinya, agar tidak terjadi kesalahan format. Sifat owah/berubah, luruh/tenang, getapan/emosional, kendel/pemberani, grasak/ kasar, lanyap/periang, wengis/kejam, sabar/sabar, ladak/sombong, dan lucu/humor perlu diapresiasi oleh kaum remaja awal, agar bisa membedakan mana yang baik dan yang buruk. Tentu saja sifat tenang, pemberani, sabar, periang, dan jenaka sangat baik untuk dimiliki, sedangkan sifat berubah-ubah, emosional, kasar, kejam, dan sombong tidak pantas untuk dimiliki.
Ukuran wayang jenis jaranan ini secara pengaturan diriada enam macam, yaitu: (1) Kecil atau seputri, bertinggi badan \pm 30 centimeter seperti Laraireng; (2) sedang atau sebambang, bertinggi badan \pm 36 centimeter seperti Abimanyu; (3) Tanggung atau seputra halus, bertinggi badan \pm 40 centimeter seperti Arjuna; (4) Tanggung atas atau seputra tangguh, bertinggi badan \pm 45 centimeter seperti Gatutkaca; (5) Besar atau seputra gagah, bertinggi badan \pm 50 centimeter seperti Bratasena; dan (6) Sangat besar atau seputra gagah tambun bertinggi badan \pm 70 centimeter seperti Kumbakarna. Dengan enam macam ukuran ini dalang pada tingkat pendidikan Sekolah Menengah Pertama dapat memainkan wayang secara layak, baik gerak dan suaranya. Layak suara berdasarkan ambitus suara remaja awal dengan mayoritas tokoh-tokoh wayang remaja awal, sedangkan layak gerak terjadi adanya kesesuaian organ tubuh wayang dengan dalang remaja awal. Jumlah wayang tersebut didominasi oleh tokoh-tokoh remaja awal, seperti Bima, Dursasana, Laraireng, Larasati, dan sebagainya, yakni berjumlah 81 tokoh wayang atau $80 \%$ dibanding dengan tokoh dewasa, seperti Prabu Kresna, Prabu Baladewa, Raden Janaka, Raden Duryudana.

\section{FORMAT WAYANG BANTHÈNGAN UNTUK DALANG REMAJAAKHIR}

Format wayang untuk dalang level remaja akhir secara jumlah, ukuran, dan ekspresi diturunkan satu tingkat dari wayang tradisi yang biasa diajarkan di Perguruan Tinggi. Jumlah minimal 144 (seratus empat puluh empat) biji dan maksimal adalah 242 (duaratus empatpuluh dua) biji, sedangkan tokoh-tokohnyameliputi: remaja Padawa dan Kurawa, remaja sahabat-sahabat Pandawa Kurawa, remaja anak-anak Pandawa dan Kurawa, remaja cucu-cucu Pandawa dan Kurawa, remaja 
Rama beserta saudara-saudaranya, remaja Rahwana saudara-saudaranya, remaja Arjunasasra, remaja dewa, dan sebagian kecil tokoh wayang dewasa dan tua seperti Pandawa dan Kurawa beserta sahabat-sahabatnya, binatang, pusaka, dan benda alam. Jumlah tokoh wayang tersebut didominasi oleh tokoh-tokoh berusia remaja akhir, yakni 125 sampai 175 tokoh wayang atau $\pm 80 \%$.

Pengelompokan wayang terdiri atas: (1) Wayang lakon, terdiri tokoh-tokoh yang akan dimainkan dalam setiap pertunjukan, maka sifatnya bergantian tergantung lakonnya; (2) Wayang simpingan, terdiri daripara tokoh remaja penuh yang tidak dijadikan sebagai wayang lakon, maka sifatnya juga bergantian; (3) Wayang dhudhahan, terdiritokoh-tokoh dewasa, tua, dan remaja awal; (4) Wayang kéwanan, terdiri dari macam-macam binatang; (4) Wayang gamanan, terdiri dari berbagai macam senjata. Jenis wayang ini diberi istilah 'banthèngan', artinya berukuran di bawah normal atau meminjam binatang banteng yang secara filosofis masa-masa puncak. Secara filosofi binatang banteng melambangkan jiwa kerakyatan atau tidak mau diganggu dan mengganggu.

Satu set wayang banthèngan untuk dalang remaja akhir terdiri enam macam ukuran atau berkurang dua tingkat dengan ukuran wayang tradisi, yaitu: (1) Kecil atau seputri, seperti Laraireng dengan tinggibadan \pm 33 centimeter; (2) Sedang atau sebambang, seperti Irawan dengan tinggi badan \pm 40 centimeter; (3) Tanggung bawah atau seputra halus, seperti Premadi dengan tinggi badan \pm 45 centimeter; (4) Tanggung atas atau seputra tangguh, seperti Gatutkaca dengan tinggi badan \pm 50 centimeter; (5) Besar atau seputra gagah, seperti Bratasena dengan tinggi badan \pm 60 centimeter; dan (6) Paling Besar atau seputra gagah tambun, seperti
Kumbakarna dengan tinggi badan \pm 70 centimeter. Dengan enam macam ukuran ini dalang pada tingkat usia remaja akhir dapat memainkan wayang secara layak, baik gerak dan suaranya. Layak suara berdasarkan ambitus suara remaja dengan mayoritas tokoh-tokoh wayang remaja penuh, sedangkan layak gerak terjadi adanya kesesuaian organ tubuh wayang dengan dalang remaja penuh atau menjelang transisi menuju ke masa dewasa baik secara jiwa dan raga.

Ekspresi wayang banthèngan terdiri: (1) owah, (2) luruh, (3) getapan, (4) kendel, (5) grasak, (6) lanyap, (7) wengis, (8) sabar, (9) ladak, (10) lucu, dan (11) culika. Dibanding dengan ekspresi dalam wayang tradisi berkurang dua macam karakter, yaitu medèni dan prenès. Pengurangan kedua ekspresi tersebut dengan pertimbangan kejiwaan kaum remaja sebagai pemain dan penonton wayang yang harus dihindari dari segala sesuatu yang bersifat menakutkan dan memancing rasa asmaranya. Pada tingkat remaja penuh ini, persoalan yang disampaikan harus sesuai dengan orientasinya, agar tidak terjadi kesalahan format. Sifat owah/berubah, luruh/ tenang, getapan/emosional, kendel/pemberani, grasak/kasar, lanyap/periang, wengis/kejam, sabar/sabar, ladak/sombong, dan lucu/humor perlu diapresiasi oleh kaum remaja penuh, agar bisa membedakan mana yang baik dan yang buruk. Tentu saja sifat tenang, pemberani, sabar, periang, danjenaka sangat baik untuk dimiliki, sedangkan sifat berubah-ubah, emosional, kasar, kejam, dan sombong tidak pantas untuk dimiliki.

FORMAT WAYANG GAJAHAN/PEDALANGAN UNTUK DALANG DEWASA

Jumlah, bentuk, ukuran, dan ekpresi wayang padhalangan diciptakan dalam rangka memenuhi kebutuhan pertunjukan, yakni antawacana dan trampil (Soetarno, 2007: 96), atau tutuk dan trampil (Nojowirongko, 1960: 57). Antawacana 
berupa ucapan/narasi/catur dalang sesuai dengan wujud dan sifat wayang, meliputi: janturan, ginem, dan pocapan (ketrampilan mulut), atau tutuk yang bermasud jelas di dalam bercerita, sedangkan trampil berupa tindakan dalang di dalam menggerakkan/sabetan boneka wayang bisa cekatan dan sesuai dengan wujud dan sifatnya (ketrampilan tangan), meliputi: cepengan, metonan, tancepan, bedholan, solah, dan entas-entasan. Tampilan naratif dan atraktif tersebut dilakukan oleh dalang untuk memerankan boneka-boneka yang secara identitas terdapat pada berbagai sumber cerita atau lakon yang diacu, yaitu: Epos Ramayana (kisah tentang seputar tokoh Rama), Epos Mahabarata (kisah keluarga besar Barata), Serat Arjunasasra (kisah seputar tokohArjunasasrabau), Kisah Dewa (kisah seputar dunia para dewa), dan Kisah Jawa (kisah seputar tokoh-tokoh dan mitosnya yang muncul di Pulau Jawa). atau tutuk, artinya jelas ceritanya, dan trampil, lihai memainkan boneka wayang

Jumlah wayang pedalangan ternyata tidak mutlak, karena disesuaikan dengan kemampuan kolektornya, tetapi ada batas minimal yang harus dipenuhi yaitu 180 biji dan maksimal 500, bahkan bisa mencapai 816 biji (Junaidi, 2016: 5071) dan 1092 biji (Sujarwo, Sumari, Wiyono, 2013: 62-1154) dalam bentuk daftar serta gambar grafisnya. Jumlahmaksimal tersebut ternyatajuga belum semuanya terwujud dalam bentuk wayang, karena baru berupa daftar dan gambar, serta kurang personalnya, seperti Kurawa berjumlah seratus satu baru tersedia \pm 10 tokoh, wayang putrèn yang seharusnya berjumlah lebih banyak justru terbalik, yakni hanya berjumlah $\pm 10 \%$ dibanding dengan wayang laki-laki atau 23-87 tokoh dari 180 sampai 1092, wayang berusia muda masih sangat sedikit jumlahnya yakni 10 tokoh, seperti misalnya Puntadewa, Bratasena, Premadi, Pinten, Tangsen, Narayana, Suryatmaja, dan sebagainya. Dengan jumlah ideal ini, maka bisa memenuhi semua tokoh yang disebutkan dalam sumber cerita/lakon, yakni mencapai ribuan dengan pertimbangan memperbanyak tokoh wayang berusia muda setingkat mahasiswa baik laki-laki maupun perempuan.

Untuk mengatasi minus boneka wayang tersebut memang bisa dilakukan dengan cara peminjaman/nyrambah tokoh yang ada (tokoh baku) diberi istilah 'wayang srambahan', tetapi dengan pertimbangan adanya kesesuaian wujud fisik (wujud kasar/bleger/rupa) dan sifat dasarnya (karakter/sipat/watak). Contoh wayang baku seperti misalnya: Rama, Sinta, Guru, Narada, Puntadewa, Drupadi, Ramaparasu, Watugunung, dan sebagainya, sedangkan srambahan antara lain: Premadi dan Arjuna Sampir, Buto Raton, Buto Patih, Buto Repatan, Bambangan, Putrèn ndhèl, Putrèn Oji, dan sebagainya. Wayang baku tidak bisa digantikan dengan wayang srambahan, karena telah dibakukan sebagai tokoh terlebih dahulu dan memiliki peranan besar dalam suatu cerita, sedangkan wayang srambahan bisa digantikan oleh tokoh baku, karena belum tersedia boneka dan kurang berperan secara aktifdi dalam suatu kisah. Mengenai teknis srambahan seperti misalnya: Premadi sampir (memakai selendang) bisa dipinjam untuk tokoh Laksmana, Arjunawijaya, Kalingga, dan sebagainya. Arjuna sampir Sekutrem, Pandu, dan sebagainya. Contoh wayang baku seperti misalnya: Rama, Sinta, Guru, Narada, Puntadewa, Drupadi, Ramaparasu, Watugunung, dan sebagainya, sedangkan srambahan antara lain: Premadi dan Arjuna Sampir, Buto Raton, Buto Patih, Buto Repatan, Bambangan, Putrèn ndhèl, Putrèn Oji, dan sebagainya. Dengan demikian, maka ideal wayang pedalangan satu set berjumlah minimal 816 biji sampai 1092 biji, bahkan lebih banyak lagi karena sebagian besar harus dibuat 
wayang bersusia muda, seperti Dursasana, Durmagati, Kartamarma, Citraksa, Citraksi, dan sebagainya dengan mengacu pada kedua sumber tersebut diatas, sehingga sesuai dengan orientasi dalang dewasa tau tua.

Ukuran wayang pedalangan terdiri atas delapan macam, yaitu: (1) Paling cilik/paling cilik, dengan tinggi tubuh \pm 27 centimeter (sakbayèn), seperti misalnya Bayi, Sang Hyang Wenang, Bondan Paksajandu, dan sebagainya; (2) Cilik/kecil, dengan tinggi tubuh \pm 35 centimeter (sakputrèn), seperti misalnya Sembadra, Srikandi, Anjani, Sinta, Utari, dan sebagainya; (3) Sedheng/sedang dengan tinggi tubuh \pm 42 centimeter (sakbambangan), seperti misalnya Abimanyu, Rukmarata, Laksmana, Irawan, dan sebagainya; (4) Tanggung/tanggung, dengan tinggi tubuh \pm 46 centimeter (sakkatongan), seperti misalnya Kresna, Rama, Arjunasasra, Yudistira, Drupada, dan sebagainya; (5) Dharal di atas tanggung, dengan tinggi tubuh \pm 50 centimeter (saktatagan), seperti misalnya Anoman, Seta, Kencakarupa, Rupakenca, dan sebagainya; (5) Magak/mendekati besar, dengan tinggi tubuh \pm 58 centimeter (sakboma), seperti misalnya Boma Narakasura, Gatutkaca, Indrajit, Gandamana, Antareja, dan sebagainya; (7) Gedhél besar, dengan tinggi tubuh \pm 70 centimeter (sakdugangan), seperti misalnya Werkudara, Rakwana, Suratimantra, dan sebagainya; dan (8) Paling gedhé/paling besar dengan tinggi tubuh \pm 78 centimeter (sakbutoraton), seperti misalnya Kumbakarna, Newatakawaca, Kurandageni, Tremboko, dan sebagainya (Junaidi, 2010: 491).

Kedelapan macam ukuran tersebut dapat dipahami sebagai dasar untuk menentukan pola ukuran wayang format pedalangan bagi dalang dewasa atau tua, karena hitungan untuk semua peralatan pertunjukan wayang bersifat anatomis, yaitu nyari (ukuran ketebalan dengan satu jari miring), geblog (ukuran panjang atau tinggi dengan bentangan telapak tangan), cengkang (ukuran panjang atau tinggi dengan rentangan ibu jari dan jari telunjuk), kilan (ukuran panjang atau tinggi dengan menggunakan rentangan ibu jari dan jari kelingking), dhepa (ukuran panjang dengan menggunakan rentangan tangan kiri dan kanan), dhadha (ukuran tinggi dengan menggunakan dada), dan bau (ukuran tinggi dengan menggunakan pundak) orang dewasa. Dengan demikian ukuran dengan menggunakan hitungan centimeter merupakan perkiraan atau sekitar/ kurang lebih saja, karena ukuran anatomi orang bersifat variatif, tetapi rentangannya ada batas minimal dan maksimal.

Ekspresi wayang untuk dalang dewasa memiliki sepuluh sifat, yaitu:(1) owah, (2) luruh, (3) getapan, (4) kendel, (5) grasak, (6) lanyap, (7) wengis, (8) sabar, (9) ladak, (10) lucu, (11) medèni, (12) culika, dan (13) prenès (Junaidi, 2010:299). Ekspresiowah/berubah adalah suatu sifat yang dapat berubah-ubah (agung, tenang, marah, sedih, gembira, dan sebagainya), bahkan dapat bersifat kontradiktifyakni seperti: wayang kayon.di depan terasa sejuk dengan bangunan rumah mewah dan pohon besar rindang, tetapi di bagian belakangnya terasa tegang dengan wujud banaspati berwarna merah membara. Ekspresi luruh/tenang adalah suatu sifat yang menunjukkan kehalusan budi dan pekerti(pikiran dan tindakan) melalui praupan (roman muka tampan dan warna kuning mas/brongsong, hitam/ ireng, dan putih/putih) dan polatan (arah pandangan melihat ke bawah atau menunduk), seperti Pandu, Bremani, Arjuna, dan sebagainya. Ekspresi getapan adalah suatu sifat yang menunjukkan ucapan dan tindakan cepat marah atau temperamental, seperti misalnya: Baladewa, Subali, Rahwana, dan sebagainya. Sifat getapan dapat ditunjukkan melalui praupan berwarna 
merah. Ekspresi kendel adalah suatu sifat pemberani dan pantang menyerah, dengan ditunjukkan melalui pasemon tajem/raut muka fokus tanpa keragu-raguan, seperti: Setyaki, Anoman, Gatutkaca, dan sebagainya. Ekspresi grasak adalah suatu sifat yang kasar dengan ditunjukkan melalui praupan jelek serba mencolok, bermulut terbuka, mata melotot, dan gigi tidak beraturan, seperti Dursasana, Rajamala, Burisrawa, dan sebagainya. Ekspresi lanyap adalah suatu sifat periang yang ditunjukkan melaluipolatan lanyap atau longok (pandangan agak ke atas), seperti Samba, Pinten, Srikandi, Karna, dan sebagainya. Ekspresi wengis adalah suatu sifat kejam yang secara fisik dapat ditunjukkan melalui roman muka raksasa dan tindakannya suka menyiksa orang lain tanpa ampun. Ekspresi sabar adalah suatu sifat yang mampu mengendalikan diri dari sifat marah, sedih, dan kecewa, dengan ditandai praupan ireng/brongsong/putih luruh (hitam menunduk) seperti: Yudistira, Abiyasa, Sembadra, Wibisana, dan sebagainya. Ekspresi ladak adalah suatu sifat tokoh wayang yang secara ekspresi mencerminkan pribadi angkuh, dengan ditandai praupan lanyap berwarna hitam dan kuning, seperti Suryatmaja, Samba, Suman, Karna, dan sebagainya. Ekspresi lucu atau jenaka adalah tokoh-tokoh wayang yang secara fisik mengesankan sifat kelucuan, dengan ditandai praupan mèsem, seperti Semar, Gareng, Petruk, Bagong. Ekspresi medèni adalah tokoh-tokoh yang memiliki wujudmenakutkan, dengan ditandai praupan, awak-awakan, dan sikilan jelek dan tidak normal, sehingga terkesan menakutkan, seperti sétanan. Ekspresi culika adalah tokohtokoh yang memiliki praupan cangkeman jewèwèk dan gusèn, sehingga terkesan tidak jujur, seperti Sengkuni, Durna, Susarma, dan sebagainya. Ekspresi prenès adalah tokoh-tokoh yang memiliki sifat romantis dengan ditandai praupan sumunar, seperti Premadi wanda pengantèn, Gatutkaca wanda gandrung, Banowati wanda bérok, dan sebagainya. Jumlah, ukuran, dan ekspresi wayang multi level beserta gambarnya dapat dilihat pada tabel dan gambar di bawah.

Tabel 1. Jumlah Wayang untuk Dalang Multi Level Usia

\begin{tabular}{|l|l|l|l|l|l|}
\hline Jenis & Kaper & $\begin{array}{l}\text { Kidang- } \\
\text { kencanan }\end{array}$ & Jaranan & Banthèngan & Padhalangan \\
\hline Level & Anak-Anak & Anak & $\begin{array}{l}\text { Remaja } \\
\text { awal }\end{array}$ & Remaja akhir & Dewasa \\
\hline Jumlah & $\mathbf{3 0 - 3 6}$ & $\mathbf{7 2 - 8 6}$ & $\mathbf{1 0 8 - 1 8 5}$ & $\mathbf{1 4 4 - 2 4 2}$ & $\mathbf{1 8 0 - 1 0 9 2}$ \\
\hline
\end{tabular}

Tabel 2. Ukuran Jenis-Jenis Wayang

\begin{tabular}{|c|c|c|c|c|c|}
\hline \multirow[t]{2}{*}{ No. } & Padhalangan & Banthèngan & Jaranan & $\begin{array}{r}\text { Kidang- } \\
\text { kencanan }\end{array}$ & Kaper \\
\hline & Dewasa/PT & Remaja/SMA & Remaja/SMP & Anak/SD & Anak/PAUD \\
\hline 1. & $\begin{array}{l}\text { Tinggi } \pm 78 \\
\text { P.Besar }\end{array}$ & $\begin{array}{l}\text { Tinggi } \pm 70 \\
\text { P.Besar }\end{array}$ & $\begin{array}{l}\text { Tinggi } \pm 60 \\
\text { P.Besar }\end{array}$ & $\begin{array}{l}\text { Tinggi } \pm 50 \\
\text { P.Besar }\end{array}$ & $\begin{array}{l}\text { Tinggi } \pm 40 \\
\text { P.Besar }\end{array}$ \\
\hline 2. & $\begin{array}{l}\text { Tinggi } \pm 70 \\
\text { Besar }\end{array}$ & $\begin{array}{l}\text { Tinggi } \pm 60 \\
\text { Besar }\end{array}$ & $\begin{array}{l}\text { Tinggi } \pm 50 \\
\text { Besar }\end{array}$ & $\begin{array}{l}\text { Tinggi } \pm 45 \\
\text { Besar }\end{array}$ & $\begin{array}{l}\text { Tinggi } \pm 37 \\
\text { Besar }\end{array}$ \\
\hline 3. & $\begin{array}{l}\text { Tinggi } \pm 58 \\
\text { Magak }\end{array}$ & $\begin{array}{l}\text { Tinggi } \pm 50 \\
\text { Magak }\end{array}$ & $\begin{array}{l}\text { Tinggi } \pm 45 \\
\text { Magak }\end{array}$ & $\begin{array}{l}\text { Tinggi } \pm 40 \\
\text { Magak }\end{array}$ & $\begin{array}{l}\text { Tinggi } \pm 34 \\
\text { Magak }\end{array}$ \\
\hline 4. & $\begin{array}{l}\text { Tinggi } \pm 46 \\
\text { Tanggung }\end{array}$ & $\begin{array}{l}\text { Tinggi } \pm 45 \\
\text { Tanggung }\end{array}$ & $\begin{array}{l}\text { Tinggi } \pm 40 \\
\text { Tanggung }\end{array}$ & $\begin{array}{l}\text { Tinggi } \pm 36 \\
\text { Tanggung }\end{array}$ & $\begin{array}{l}\text { Tinggi } \pm 30 \\
\text { Tanggung }\end{array}$ \\
\hline 5. & $\begin{array}{l}\text { Tinggi } \pm 42 \\
\text { Sedang }\end{array}$ & $\begin{array}{l}\text { Tinggi } \pm 40 \\
\text { Sedang }\end{array}$ & $\begin{array}{l}\text { Tinggi } \pm 36 \\
\text { Sedang }\end{array}$ & $\begin{array}{l}\text { Tinggi } \pm 30 \\
\text { Sedang }\end{array}$ & $\begin{array}{l}\text { Tinggi } \pm 27 \\
\text { Sedang }\end{array}$ \\
\hline
\end{tabular}




\begin{tabular}{|l|l|l|l|l|l|}
\hline 6. & Tinggi \pm 35 & Tinggi \pm 33 & Tinggi \pm 30 & Tinggi \pm 27 & Tinggi \pm 24 \\
& Kecil & Kecil & Kecil & Kecil & Kecil \\
\hline 7. & Tinggi \pm 27 & Tinggi \pm 23 & Tinggi \pm 22 & Tinggi \pm 21 & Tinggi \pm 20 \\
& P. Kecil & P. Kecil & P. Kecil & P. Kecil & P. Kecil \\
\hline
\end{tabular}

Tabel 3. Model Tatahan Wayang Mulai Tiga Sampai Sebelas Macam

\begin{tabular}{|l|l|l|l|l|l|}
\hline No. & Kaper & Kidangkencanan & Jaranan & Banthèngan & Padhalangan \\
\hline 1 & Tratasan & Tratasan & Tratasan & Tratasan & Tratasan \\
\hline 2. & Bubukan & Bubukan & Bubukan & Bubukan & Bubukan \\
\hline 3. & Kukon & Kukon & Kukon & Kukon & Kukon \\
\hline 4. & - & Gabahan & Gabahan & Gabahan & Gabahan \\
\hline 5. & - & Inten-intenan & Inten-intenan & Inten-intenan & Inten-intenan \\
\hline 6. & - & - & Untu walang & Untu walang & Untu walang \\
\hline 7. & - & - & Srunèn & Srunèn & Srunèn \\
\hline 8. & - & - & - & Bubuk iring & Bubuk iring \\
\hline 9. & - & - & - & Emas-emasan & Emas-emasan \\
\hline 10. & - & - & - & - & Patran \\
\hline 11. & - & - & - & - & Seritan \\
\hline
\end{tabular}

Tabel 4. Model Sunggingan Wayang Mulai Satu sampai Lima Macam

\begin{tabular}{|c|c|c|c|c|c|}
\hline No. & Kaper & Kidangan & Jaranan & Banthéngan & Gajahan \\
\hline 1 & $\begin{array}{l}\text { Merah/putih } \\
\text { kuning/biru } \\
\text { hitam }\end{array}$ & Putih & Puth & Putih & Putih \\
\hline 2 & - & $\begin{array}{l}\text { Merah/kuning/ } \\
\text { biru/hitam }\end{array}$ & $\begin{array}{l}\text { Merah muda/ } \\
\text { Kuning } \\
\text { muda/biru } \\
\text { muda/hijau } \\
\text { muda/hitam } \\
\text { muda }\end{array}$ & $\begin{array}{l}\text { Merah muda/ } \\
\text { kuning } \\
\text { muda/biru } \\
\text { muda/hijau } \\
\text { muda/hitam } \\
\text { muda }\end{array}$ & $\begin{array}{l}\text { Merah muda/ } \\
\text { kuning } \\
\text { muda/biru } \\
\text { muda/hijau } \\
\text { muda/hitam } \\
\text { muda }\end{array}$ \\
\hline 3 & - & - & $\begin{array}{l}\text { Merah tua/ } \\
\text { kuning tua/ } \\
\text { biru tua/hijau } \\
\text { tua/hitam }\end{array}$ & $\begin{array}{l}\text { Merah tua/ } \\
\text { kuning tua/ } \\
\text { biru tua/ } \\
\text { hijau tua/ } \\
\text { hitam }\end{array}$ & $\begin{array}{l}\text { Merah tua/ } \\
\text { kuning tua/ } \\
\text { biru tua/ } \\
\text { hijau tua/ } \\
\text { hitam }\end{array}$ \\
\hline 4 & - & - & $\begin{array}{l}\text { Merah sangat } \\
\text { tua pekat/ } \\
\text { kuning sangat } \\
\text { tua/biru } \\
\text { sangat satua/ } \\
\text { hijau sangat } \\
\text { tua/hitam }\end{array}$ & $\begin{array}{l}\text { Merah sangat } \\
\text { tua pekat/ } \\
\text { kuning sangat } \\
\text { tua/biru } \\
\text { sangat satua/ } \\
\text { hijau sangat } \\
\text { tua/hitam }\end{array}$ \\
\hline 5 & - & - & $\begin{array}{l}\text { Kuning emas/ } \\
\text { prada/brom }\end{array}$ \\
\hline
\end{tabular}



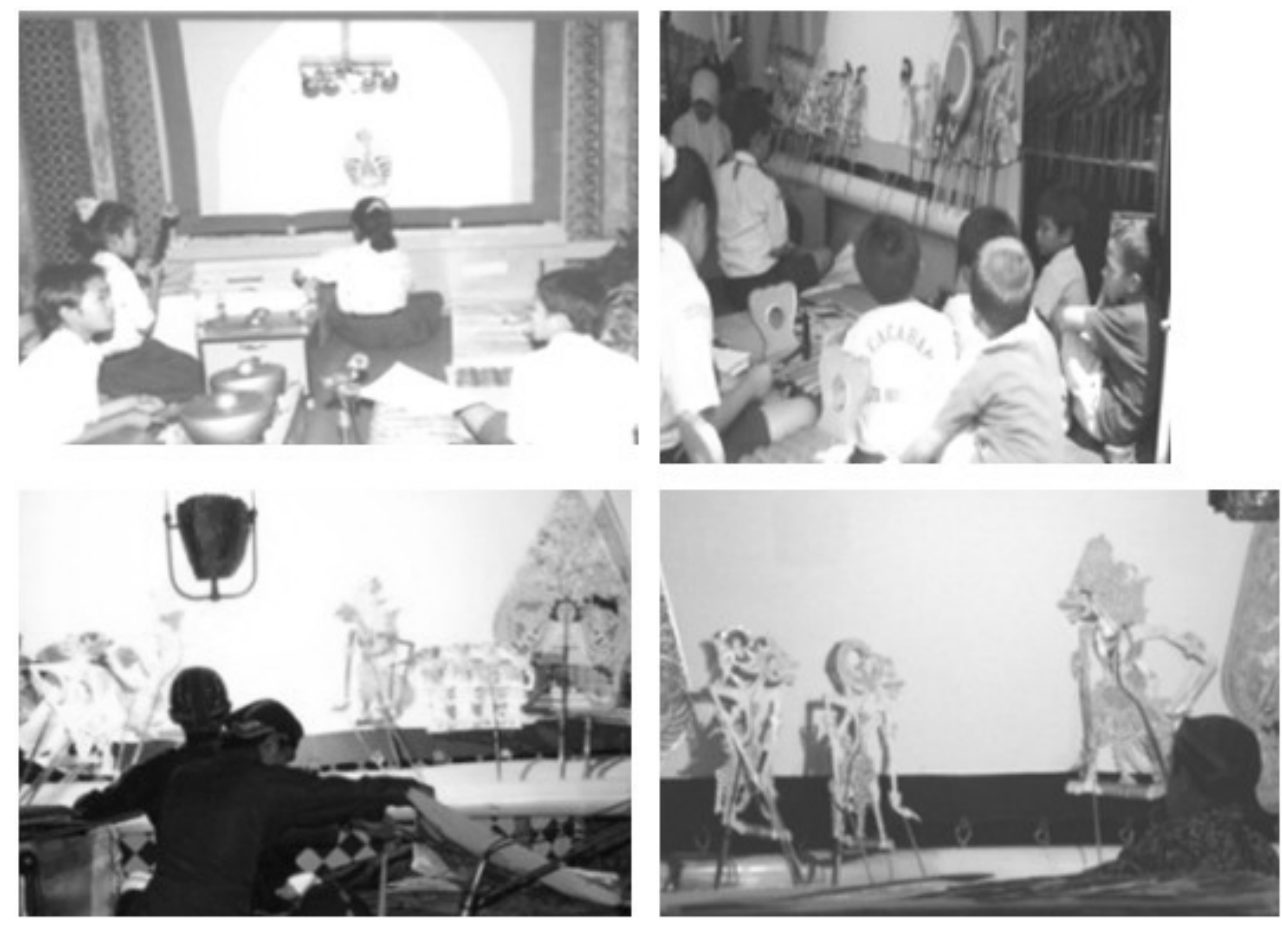

Gambar 1. Contoh boneka wayang multi level untuk dalang multi level usia, yaitu level anak (kiri), level remaja (kedua dari kiri), level muda (ketiga dari kiri), dan level dewasa atau tua (kanan) (Foto: Junaidi, 2006, 2013, 2014, dan 2015).

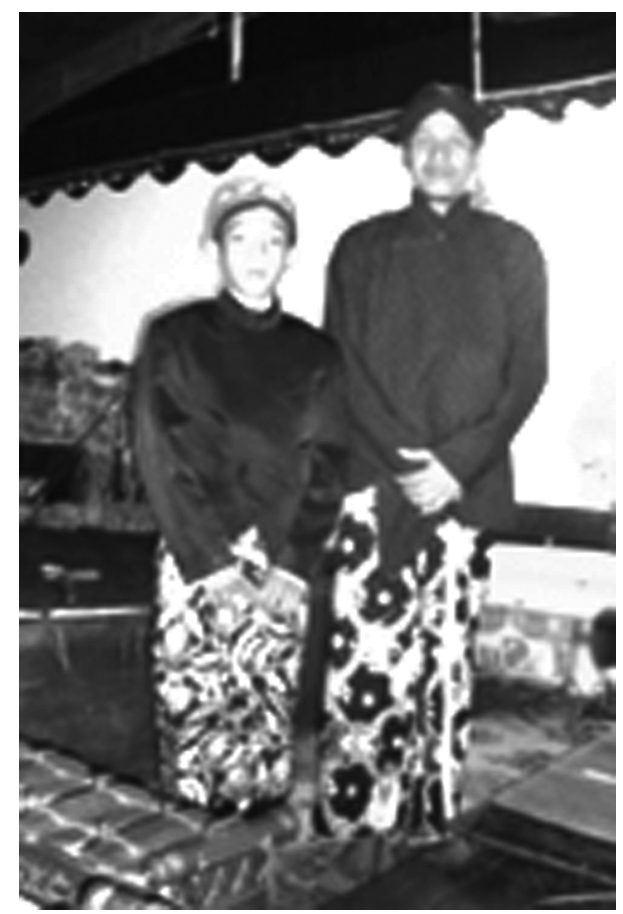

Gambar 2. Cotoh ukuran fisik dalang usia anak (kiri) dan dewasa (kanan) (Foto: Junaidi, 2010). 


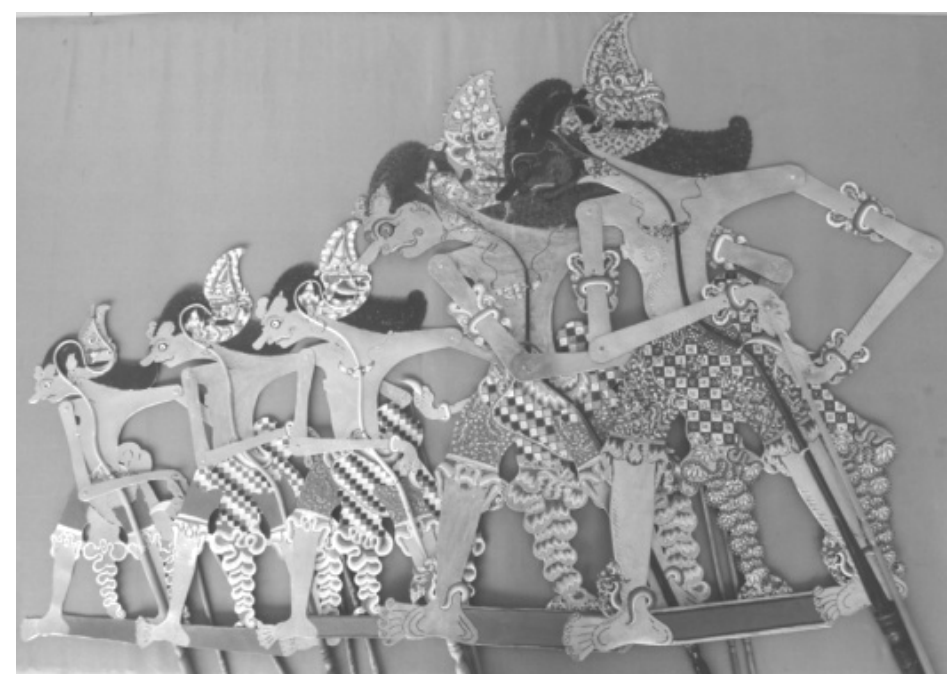

Gambar 3. Wujud wayang berbagai model untuk dalang anak-anak (kiri), anak (kedua dari kiri), remaja awal (ketiga dari kiri), remaja akhir (keempat dari kiri), dan dewasa (kanan) (Foto: Junaidi, 2017).
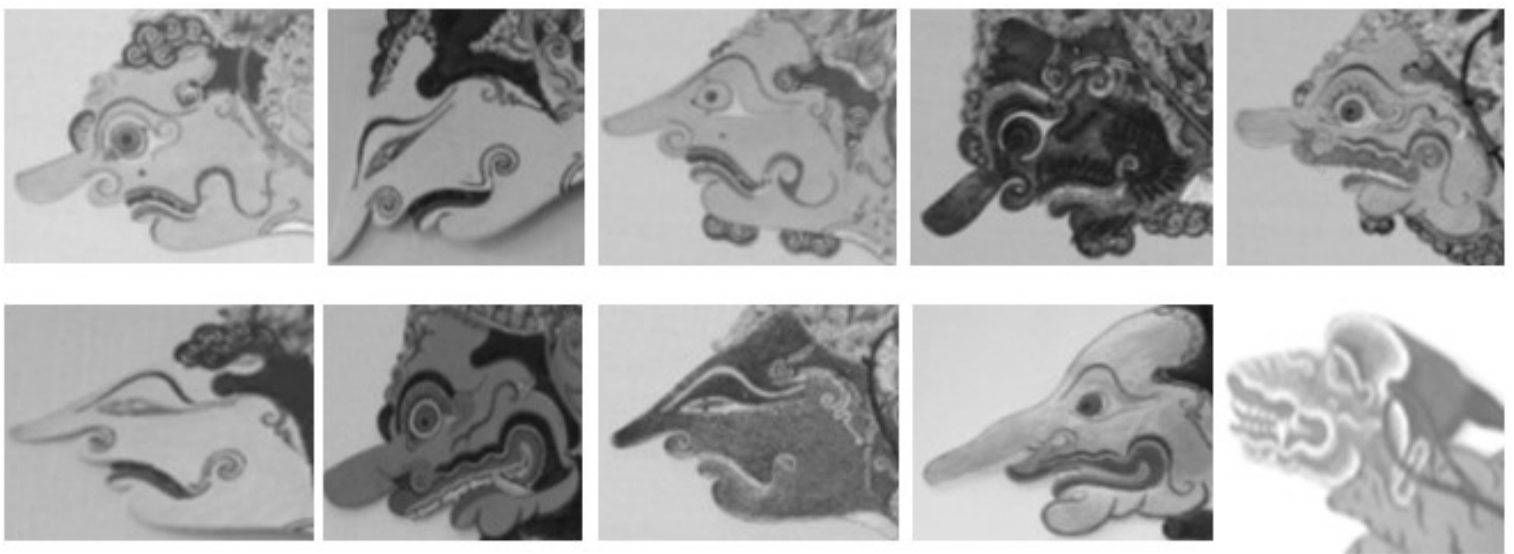

Gambar 4. Ekspresi wayang owah (kiri), luruh (kedua dari kiri), getapan (ketiga dari kiri), kendel (keempat dari kiri), grasak (kelima dari kiri), lanyap (keenam dari kiri), wengis (ketujuh dari kiri), ladak (kedelapan dari kiri), lucu (kesembilan dari kiri), dan medèni (kanan) (Foto: Junaidi, 2016).

Bedasarkan jumlah, ukuran, dan ekspresi wayang tradisi tersebut dapat dipahami bahwa formatnya untuk dalang dewasa atau tua, sehingga memiliki banyak tokoh atau berjumlah banyak minimal 180 personal, berukuran besar dimulai dari 27 centimeter sampai 76 centimeter, dan berekspresi kedewasaan dengan ditandai raut muka/praupan orang dewasa dan tua, seperti dahi lengar/lebar dan mlengkuk-mlengkuk/ berlipat, sebagian sudah berkumis dan berjenggot serta jawès. Tanda praupan lainnya adalah warna wajah bersifat simbolis seperti merah/ emosional, putih/kejujuran, hitam/abadi, dan biru/tidak stabil. Di samping tanda melalui wajah juga ditandakan melalui tubuh (awak-awakan) secara fisik berupa payudara bagitokoh perempuan 
(putrèn) dan bulu di bagian tubuh, tangan, dan kaki berupa (simbar). Hal-hal semacam ini lebih sesuai untuk dalang dewasa dan tua yang secara fisik dan jiwa telah menguasai atau sesuai dengan atmosfir berpikir dan bertindaknya.

\section{SIMPULAN}

Hasil pembahasan tersebut di atas dapat disimpulkan, bahwa wayang untuk dalang multi level usia bersifat multi level jumlah, ukuran, dan bentuk, karena kondisi jiwa dan fisik dalang juga bersifat multi level, sehingga harus disesuaikan agar penampilannya sesuai dengan kondisi perkembangannya. Semakin tinggi tingkat usia semakin tinggi pula tingkat penguasaannya, sehingga jumlah tokoh, ukuran tubuh, dan ekspresi anatomi diformat meningkat, yaknitingkat 1 untuk format anak-anak, tingkat 2 untuk format anak, tingkat 3 untuk format remaja awal, tingkat 4 untuk format remaja akhir, dan tingkat 5 untuk format dewasa. 


\section{DAFTAR PUSTAKA}

Darsomartono, S. 1978 Tuntunan Padhalangan. Surakarta: Yayasan Pasinaon Dhalang ing Mangkunagran.

Haryanto, S. 1991 Seni Rupa Wayang Kulit. Jakarta: PT. Pustaka Utama Grafiti.

Junaidi. 2010. "Pakeliran Wayang Kulit Purwa Gaya Surakarta oleh Dalang Anak. Yogyakarta: Disertasi untuk Memeperoleh Derajat Sarjana S-3, Program Studi Pengkajian Seni Pertunjukan dan Seni Rupa, Sekolah Pascasarjana, Universitas Gadjah Mada.

Juanidi. 2016. Pengetahuan Dasar Seni Pedalangan. Yogyakarta: CV. Arindo Nusa Media.

Nawawi, H. Hardani dan Martini, Mimi. 2005. Penelitian Terapan. Yogyakarta: Gadjah Mada Press.

Piaget, Jean. 1995 Strukturalisme. Trans. Hermoyo. Jakarta: Yayasan Obor Indonesia.

Sajid, RM. 1958 Bauwarna Wayang. Yogyakarta: P.T. Percetakan Republik Indonesia.
Sastroamidjojo, Seno.1964 Renungan Tentang Pertunjukan Wayang Kulit. Jakarta: Kinta Jakarta.

Soekatno. 1992. Mengenal Wayang Kulit Purwa. Semarang: C.V. Aneka Ilmu.

Soetarno, Sunardi, dan Sudarsono. 2007. Estetika Pedalangan. Surakarta: Institut Seni Indonesia Surakarta bekerjasama dengan CV. Adji Surakarta.

Soetrisno, R. 1974. Kawruh Wayang. Surakarta: Akademi Seni Karawitan Indonesia.

Sudjawo, Heru S, Sumari, Undung Wiyono. 2013 Rupa \& Karakter Wayang Purwa. Jakarta: Kakilangit Kencana Perdana Media Group, Cetakan ke-2.

Suroso. 2009 Penelitian Tindakan Kelas. Yogyakarta: Pararaton.

Suryabrata, Sumadi. 1987. Psikologi Pendidikan. Jakarta: CV. Rajawali. 